\title{
Observatório de
}

Inovação do Turismo

BRASIL

Revista Acadêmica

ISSN 1980-6965

www.ebape.fgv.br/revistaoit

Sensacional!

\section{0 mercado de cruzeiros marítimos no Brasil: uma análise da demanda potencial no estado do Rio de Janeiro}

The maritime cruises market in Brazil: an analysis of potential demand in the state of Rio de Janeiro

Fabiana Braga Leal

Maria de Fatima Soares

Natalia Pacheco

Teresa Catramby

Thays Venturim Guimarães

\section{Resumo:}

Este trabalho versa sobre aspectos de um setor em expansão: o de cruzeiros marítimos. Objetivou-se pesquisar e analisar um público específico: pessoas que nunca realizaram uma viagem de cruzeiro - grupo que representa uma demanda potencial para o setor. Construiu-se o referencial teórico com base em temáticas de turismo náutico, grandes eventos e impacto econômico. Como metodologia, realizou-se pesquisa de campo, na qual a coleta dos dados se deu por meio de questionários, com perguntas abertas e fechadas, enviados a um público aleatório com utilização da plataforma eletrônica. Delimitou-se a amostra entre cem pessoas residentes no estado do Rio de Janeiro. Tabularam-se os resultados por meio de tratamento estatístico e, com os dados analisados, espera-se contribuir para o planejamento deste setor.

Palavras-chave: cruzeiros marítimos, demanda potencial, Porto do Rio de Janeiro

Artigo recebido em janeiro de 2012 e aceito em agosto de 2012 


\section{Abstract:}

This paper describes aspects of an expanding industry, the cruise line. The aim was to investigate and analyze a specific public: people who have never done a cruise trip, a group that represents a potential demand for the sector. The theoretical framework was constructed based on the themes of nautical tourism, major events and economic impact. The methodology carried out a field survey in which data collection was through questionnaires with open and closed questions and sent to a random public using an electronic platform. The sample was surrounded by a hundred people residents in the State of Rio de Janeiro. The results were tabulated by statistical methods and we hope that data analysis will contribute to the planning of this sector.

Key words: Cruises, potential demand, Rio de Janeiro's Port

\section{Introdução}

O turismo de cruzeiros, no mundo, remonta ao início da década de 1960 com a queda da indústria de barcos transoceânicos e a entrada das primeiras viagens aéreas sem escala entre Estados Unidos e Europa. As décadas de 1970 a 1990 foram períodos de crescimento moderado na indústria e, a partir da década seguinte, esse tipo de viagem chegou à Europa, Ásia e Oceania, iniciando o período de expansão (KESTER, 2002; BRIDA et al., 2010).

No Brasil, a presença de cruzeiros deu-se a partir de 1996, com a emenda na Constituição federal que permitiu novamente a cabotagem na costa brasileira, mas, somente em 1997, foi possível sentir os efeitos dessa liberação na navegação. Na temporada de verão 1999-2000, teve destaque a chegada do navio Splendor of the Seas, como também a presença da Costa Cruzeiros, MSC, CVC e entrada de várias outras armadoras' no mercado brasileiro, o que justifica a investigação de tão recente modalidade de turismo (BOITEUX, 2010).

O Brasil é um país que apresenta um conjunto de condições naturais propícias para o desenvolvimento do turismo náutico², em razão do vasto litoral, com mais de sete mil quilômetros de extensão, clima tropical e diversidade de recursos naturais. Esse segmento do turismo vem-se configurando, pois, como uma área favorável para novos investimentos.

De acordo com a Associação Brasileira de Representantes de Empresas Marítimas ABREMAR - no ano de 2010, deu-se a mais longa temporada de cruzeiros no País se comparada a outros períodos. Foram mais de novecentos mil passageiros em trânsito, o que equivale

${ }^{1} \mathrm{O}$ termo "armadoras" é utilizado para referir-se às empresas que trabalham nesse segmento.

${ }^{2} \mathrm{O}$ turismo naútico caracteriza-se pela utilização de embarcações com a finalidade de movimentação turística (MTUR). 
a um aumento de 66\% em comparação ao registrado no ano anterior. Para a ABREMAR (2010), o principal motivador desse crescimento foi o aumento de renda da população, especialmente em relação à classe $C^{3}$, o que significou um contingente de pessoas com recursos financeiros disponíveis para viagens a lazer. Dois dos principais motivos que propiciaram o aumento da procura por essa modalidade de turismo, entre os brasileiros, foram (1) o aumento do poder de compra de parte da população e (2) a diminuição da taxa de desemprego, principalmente em relação à classe média.

Um dos pontos de maior atenção para a continuidade da operação marítima no Brasil é o custo operacional, que está entre os mais altos do mundo. Destaca-se também a necessidade de desenvolver novos destinos, rotas e portos capacitados a receber navios de cruzeiro. No Brasil, há potencialidades de criação de novos destinos e um mercado consumidor forte para essa oferta. Além dos cruzeiros de cabotagem4, que se fazem no litoral do Brasil, ainda há os de longo curso (internacionais) ${ }^{5}$, em que se realizam escalas no País e que trazem um quantitativo alto de turistas estrangeiros, promovendo a entrada de divisas para a economia brasileira.

Conforme destacado por Mattos (2009), levando-se em consideração a balança comercial do turismo, seriam mais vantajosos para o Brasil os cruzeiros de longo curso, tendo em vista que todos os gastos aqui realizados - por navios e passageiros - representam exportação de serviços, beneficiando a economia do País. Em contrapartida, os cruzeiros de cabotagem atuam com receitas auferidas pelos navios que são contabilizadas como importação de serviços - sendo os recursos transferidos para o exterior, o que desequilibra a balança de turismo.

Segundo Brida et al. (2010), em geral, os benefícios econômicos do setor de cruzeiros provêm basicamente de três aspectos: (1) os gastos que os passageiros realizam quando estão em terra, fazendo excursões e comprando artesanatos, roupas, alimentos e bebidas; (2) os gastos da tripulação com os mesmos itens mencionados e (3) o consumo gerado pela própria embarcação, tais como serviços portuários, rebocador, água potável.

Entre outras razões, a expansão observada no setor de cruzeiros - não apenas mundialmente, mas especialmente no Brasil —justifica a relevância deste trabalho. Os avanços ocorridos no setor, principalmente nos últimos anos, têm levado empresas marítimas a adaptarem-se à nova configuração de mercado, por constituir-se um setor capaz de projetar novas ações empreendedoras.

Citem-se, como exemplos de empresas empreendedoras, a MSC e a operadora de viagens CVC, que popularizaram a venda de pacotes em cruzeiros, consolidando, no mercado de viagens e turismo, a posição de provedoras de viagens acessíveis, pois passaram a oferecer ao novo público

${ }^{3}$ Os critérios para classes sociais podem ser obtidos pelo documento CCEB - Critérios para Classificação Econômica Brasil -, divulgado pela ABEP - Associação Brasileira de Empresas de Pesquisa - no site http://www.abep.org/novo/Content. aspx?ContentID=301.

4 "São cruzeiros despachados para o Brasil por seus armadores durante a baixa sazonalidade em suas áreas centrais de atuação. Sua operação ocorre exclusivamente na costa brasileira, sendo os brasileiros o mercado-alvo, senão único" (MATTOS, 2009). ${ }^{5}$ São cruzeiros que partem de portos internacionais e alcançam o Brasil com passageiros estrangeiros (MATTOS, 2009). 
facilidades de pagamento, buscando com isso ampliar a dinâmica dos destinos com os quais trabaIham, por meio da promoção de produtos para segmentos de mercado que antes não vislumbravam.

Pesquisa encomendada pela Cetelem BGN (2010), financeira do grupo francês BNP Paribas, em parceria com o Instituto de Pesquisa IPSOS, sobre o perfil do consumidor brasileiro, mostra que as classes D e E de consumo encolheram nos últimos cinco anos. Desde 2007, de acordo com a referida pesquisa, na classe $C$, concentra-se o maior número de brasileiros.

\section{Figura 1: Distribuição da população brasileira por classe de consumo}

\begin{tabular}{|c|cccccc}
\hline 2005 & 2006 & 2007 & 2008 & 2009 & & \\
\hline $15 \%$ & $18 \%$ & $15 \%$ & $15 \%$ & $16 \%$ & & $\mathrm{C} / \mathrm{B}$ \\
\hline $34 \%$ & $36 \%$ & $46 \%$ & $45 \%$ & $49 \%$ & & $\mathrm{D} / \mathrm{C}$ \\
\hline $51 \%$ & $46 \%$ & $39 \%$ & $40 \%$ & $35 \%$ & & \\
\hline
\end{tabular}

Base: 1.500

Fonte: Pesquisa Cetelem - Ipsos 2005/2006/2007/2008/2009

Diante dessas premissas, observa-se a vsão estratégica das empresas de cruzeiros marítimos ante a baixa demanda por produtos de luxo e a tendência de buscar, nas novas classes consumidoras, um novo mercado potencial.

Considerando-se os aspectos acima, torna-se relevante identificar as oportunidades e os desafios para o crescimento do segmento náutico no Brasil, em especial no que se refere ao mercado de cruzeiros. A Fundação Getulio Vargas - FGV -, em parceria com a Associação Brasileira de Cruzeiros Marítimos - ABREMAR - , realizou, em 2011, uma grande pesquisa para identificar o perfil e algumas expectativas dos viajantes que tiveram a experiência de usufruir de um cruzeiro na temporada de 2010.

Como forma de dar continuidade, no presente trabalho, objetiva-se apresentar os resultados de uma recente pesquisa realizada com o público do Rio de Janeiro que ainda não teve a experiência de realizar um cruzeiro.

Inicialmente, optou-se por apresentar uma breve reflexão sobre o setor de cruzeiros e, em seguida, como forma de complementar os resultados da pesquisa, destacou-se a importância do Projeto Porto Maravilha, que pode representar uma nova era tanto no setor de cruzeiros, como na valorização de um espaço da cidade que, por muito tempo, foi esquecido e marginalizado.

Em seguida, apresentam-se os resultados da pesquisa realizada pela FGV e ABREMAR, a fim de, posteriormente, traçar um paralelo entre o perfil da demanda real e os resultados obtidos neste trabalho. 


\section{0 mercado de cruzeiros}

Em um país com dimensões continentais, que abriga a maior reserva de água doce do planeta e mais de sete mil quilômetros de costa, há muito a explorar no segmento do turismo náutico. O Brasil é notoriamente um dos países do mundo que apresenta condições naturais propícias para o desenvolvimento do turismo marítimo, por ter vasto litoral banhado pelo oceano Atlântico, clima tropical, além de cenário natural favorável, que propicia a prática desse segmento do turismo.

Há pouco tempo, grande parte dos cruzeiros marítimos era realizada no Caribe e na costa norte-americana, e a participação da América do Sul, incluindo o Brasil, ainda se apresentava bastante reduzida. Contudo o elevado potencial brasileiro para o fomento desse segmento, além do fato de o mercado de cruzeiros marítimos no Caribe, segundo Cooper (2001), já apresentar sinais de saturação, facilitou a ampliação desse segmento no mercado nacional.

Como resultado dessa ampliação, na última década, constatou-se um considerável aumento no fluxo de cruzeiros marítimos no litoral brasileiro, com a ampliação de leitos nos navios e de rotas por parte dos armadores. Na temporada 2010-2011, contabilizou-se um impacto econômico de cerca de R\$1,3 bilhão. Parte desse incremento justifica-se pelo controle da inflação, maior formalização do mercado do trabalho e aumento da renda da população, registrando-se maior procura por mercados de lazer (CNC, 2011).

$\mathrm{Na}$ temporada 2010-2011, foram vinte navios e quase oitocentos mil passageiros transportados. Entretanto, na contramão desse desenvolvimento, na temporada 2011-2012, caiu para 17 navios, o que representa uma queda de 17\% na oferta. Esse declínio, apesar do crescimento da demanda, é justificado pelo anseio de um futuro com melhores condições que suportem a atual demanda. Em recente entrevista, André Pousada, vice-presidente executivo da ABREMAR menciona:

[...] muita gente pode achar que o mercado de cruzeiros no Brasil já amadureceu o bastante e que esse é o equilíbrio entre a oferta e a demanda. Mas não. Existem sim uma demanda reprimida e um potencial gigantesco.

Pousada afirma que o grande problema é o espaço físico, visto que não existem mais opções de locais para atracação de navios, evidenciando a necessidade de novos destinos e novos portos para recebê-los. Um dos itens que também merece atenção é a questão da sustentabilidade, pois não é somente o terminal que deve estar adequado para receber o navio, mas toda a área do porto e, acima de tudo, o entorno, já que hoje existem navios que trazem 
mais de quatro mil passageiros. Números como esse justificam a necessidade de uma logística de transporte e um receptivo qualificado para atender às necessidades dos turistas.

Fica evidente, nesse caso, que o impeditivo para o crescimento da atividade no Brasil não é a ausência de demanda, mas sim a infraestrutura portuária inadequada. Graças a essa realidade, algumas companhias marítimas atuam de forma limitada em alguns portos, como o caso do Rio de Janeiro e de Santos. Atualmente, esses portos conseguem operar simultaneamente apenas com sete navios.

\section{Infraestrutura portuária no estado do Rio de Janeiro}

A costa brasileira apresenta hoje 34 portos públicos, sendo 131 terminais privativos, 122 de uso privativo misto (presença de carga) e nove exclusivos, assim como as estações de transbordo de carga, as instalações portuárias públicas de pequenos portes, os terminais de turismo e 180 iates clubes.

A questão crucial referente aos portos, já levantada neste artigo, está relacionada com a infraestrutura portuária, que é incipiente na recepção e circulação dos turistas, na estrutura do entorno (restaurantes, pontos de táxis, hotéis), como também em atividades operacionais de carga - que hoje são inadequadas. O porto da cidade do Rio de Janeiro, por exemplo, já apresenta saturação, sendo necessária a aplicação de projetos para atender à demanda de grandes navios, às vezes seis ao mesmo tempo, com circulação (embarque e desembarque) de aproximadamente mil a três mil passageiros.

Estudos realizados pela ABREMAR (2010) com o objetivo de mapear as necessidades do porto da cidade do Rio de Janeiro e dos terminais de turismo para desembarque dos passageiros, em Cabo Frio, Búzios, Paraty, Angra dos Reis e llha Grande ${ }^{6}$, mostram o fluxo de navios e escalas realizados nesses portos e uma projeção da quantidade de passageiros, conforme é possível observar na Tabela 1.

Tabela 1: Fluxo nos portos do estado do Rio de Janeiro

\begin{tabular}{|c|c|c|c|}
\hline $\begin{array}{l}\text { PORTO/TERMINAL } \\
\text { TURÍSTICO }\end{array}$ & NAVIOS & ESCALAS & $\begin{array}{c}\text { TOTAL DE } \\
\text { PASSAGEIROS } \\
\text { (PROJEC̣ÃO) }\end{array}$ \\
\hline Rio de Janeiro* & 19 & 235 & 566,903 \\
\hline 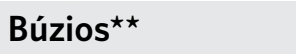 & 18 & 199 & 417,987 \\
\hline Ilha Grande ${ }^{\star \star}$ & 11 & 29 & 67,937 \\
\hline Angra dos Reis ${ }^{\star \star}$ & 5 & 36 & 67,640 \\
\hline Cabo Frio ${ }^{\star \star}$ & 5 & 17 & 28,818 \\
\hline Paraty ${ }^{\star \star}$ & 1 & 1 & 2,736 \\
\hline
\end{tabular}

\footnotetext{
${ }^{6}$ É possível observar a descrição do porto e de terminais turísticos do estado Rio de Janeiro no Apêndice 1, ao final deste artigo.
} 
É fundamental que ações do governo brasileiro sejam realizadas nos locais, principalmente pensando na demanda de grandes eventos, como a Copa do Mundo de 2014 cuja expectativa é receber 15 mil turistas que chegarão em veleiros ou iates - e os iates clubes também não têm como recepcioná-los -, além dos navios de cruzeiro que atuarão com o perfil de hospedagem para atender à deficiência da hotelaria nos períodos de megaeventos.

\subsection{Projeto Porto Maravilha — perspectivas para um novo cenário}

A necessidade de reestruturação da zona portuária é justificada pelo crescimento consistente que o Brasil vem apresentando - e a cidade do Rio de Janeiro mostra sinais de uma nova dinâmica econômica, que vem impulsionada pelos grandes eventos que ocorrerão na cidade nos próximos anos. Assim, o projeto urbano - Porto Maravilha - surge com o objetivo de preparar a região portuária, que há anos não recebe incentivos de melhorias, e integrá-la ao processo de desenvolvimento.

Por meio do projeto Porto Maravilha, objetiva-se realizar a mudança do eixo de desenvolvimento imobiliário para o centro da cidade, melhorando a qualidade de vida dos atuais moradores da localidade, ampliando a área residencial e valorizando, assim, o patrimônio no âmbito da sustentabilidade ambiental e socioeconômica da área (CDURP, 2011). Esse projeto é de iniciativa da Prefeitura do Rio de Janeiro, com apoio dos governos estadual e federal.

A área tem localização geográfica privilegiada, próxima ao aeroporto Santos Dumont com fácil acesso ao aeroporto Internacional Antônio Carlos Jobim e aos principais atrativos da cidade - Pão de Açúcar, Copacabana, Corcovado, Maracanã. Em 2010, a população no entorno era de aproximadamente 28 mil habitantes e, hoje, ocupa uma área total de cinco milhões de metros quadrados (CDURP, 2011).

Desde os anos de 1800, essa localidade está inserida nas mudanças estruturais espaciais e geográficas da cidade. Pode-se perceber, nas Figuras 1 e 2, sua relevância histórica. Na Figura 2, destaca-se, no ano de 1817, o predomínio, na paisagem, do Largo de São Francisco da Prainha e do Armazém do Sal; já em 1930, observa-se o edifício "A Noite", a Praça Mauá, o Arsenal da Marinha, o Palacete D. João VI e o Cais da Gamboa. Por fim, na paisagem dos anos 2000, destaca-se o prédio da Polícia Federal, a avenida Perimetral - que atualmente está em projeto de demolição -, o píer Mauá e, na área central, os edifícios comerciais, com destaque para o edifício Rio Branco 1. 
Figura 1: Área do Porto Maravilha: os impactos das ações humanas

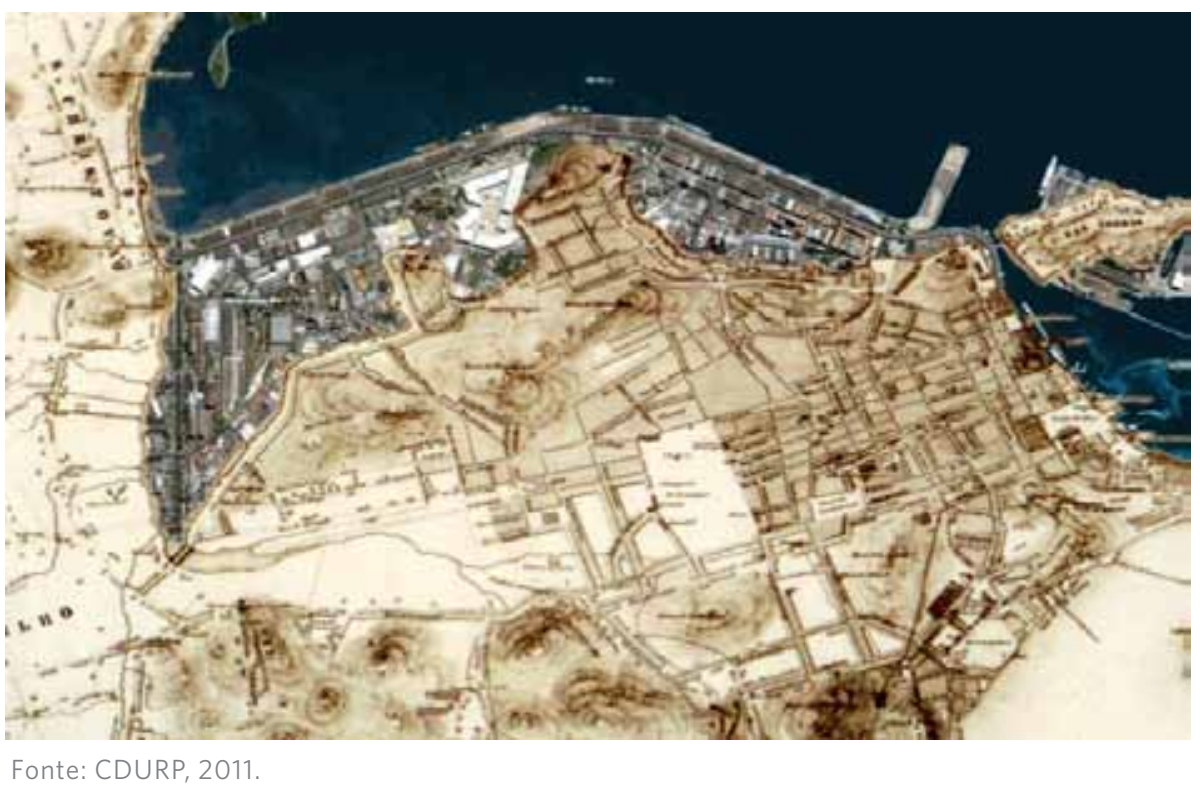

Figura 2: Relevância histórica da zona portuária

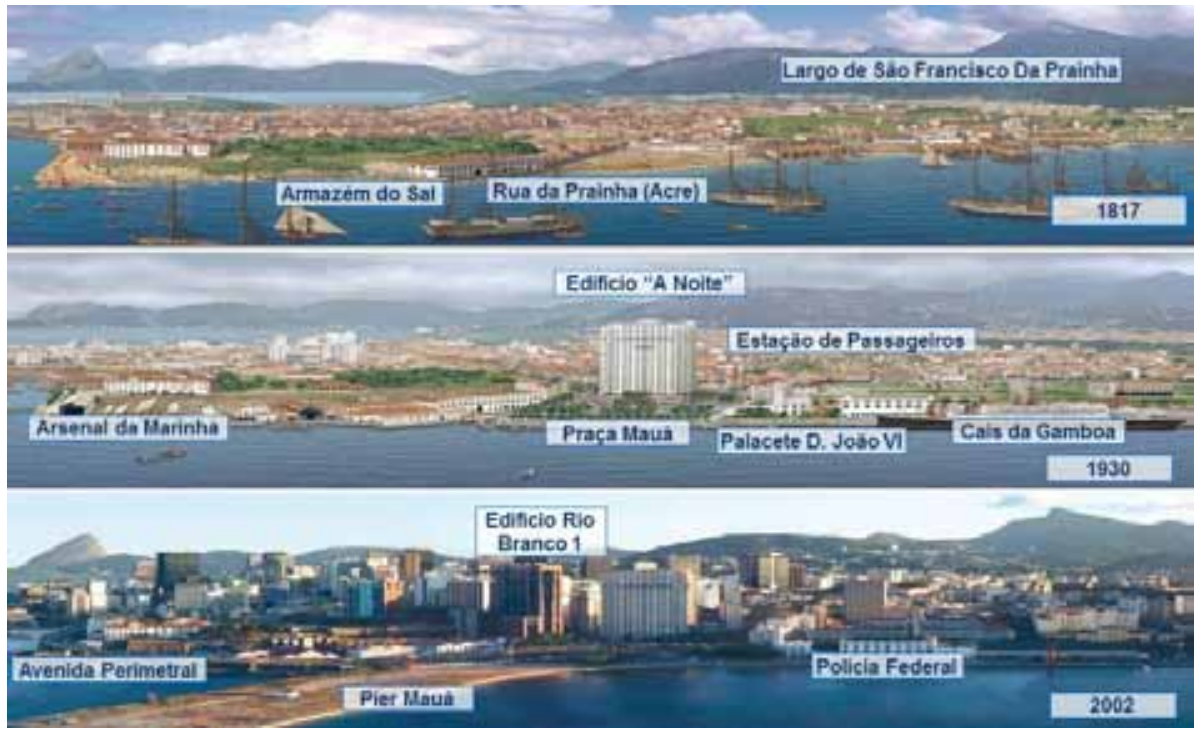

Fonte: CDURP, 2011

As questões estruturais de saneamento e ambientação do Porto Maravilha são entraves para o desenvolvimento da localidade, que apresenta apenas 2,5\% de faixa de áreas verdes; os lançamentos de esgoto são feitos na rede de drenagem, nos rios e no canal do mangue, e a acumulação de resíduos implica crônicos alagamentos no entorno (CDURP, 2011).

Trata-se de uma área portuária que, nas temporadas de cruzeiros marítimos, recebe um grande quantitativo de turistas. Apesar disso, está visualmente decadente, pois faltam serviços e equipamentos relacionados com hospedagem, restaurantes e base de apoio para transportes, a 
fim de proporcionar o deslocamento seguro de turistas. Mudar o atual panorama é fundamental para resgatar a história turístico-cultural da localidade.

Nesta década, a cidade do Rio de Janeiro estará sediando importantes eventos e megaeventos: o Rock in Rio, realizado em 2011 e com previsão para 2013; a Rio + 20, em 2012; a Copa das Confederações da FIFA, em 2013; o megaevento - Copa do Mundo FIFA -, em 2014; a Copa América e o aniversário dos 450 anos da cidade em 2015; e, por fim, em 2016, os Jogos Olímpicos Rio 2016. Tendo em vista esses acontecimentos, mostra-se um cenário propício para investimentos no setor turístico, em especial no que se refere à zona portuária, no intuito de garantir aos turistas que virão à cidade uma estrutura eficiente e um ambiente agradável (CDURP, 2011), fatores que justificam a importância da execução do projeto em questão.

Pelo atual projeto Porto Maravilha, visa-se a abrir oportunidades para os residentes, comerciantes e visitantes, no sentido de proporcionar melhorias nos imóveis que podem alocar empreendimentos comerciais, hoteleiros, residenciais, de serviço e culturais. A cidade está com déficit de unidades hoteleiras para atender à demanda da Copa e das Olimpíadas e o projeto também surge com o objetivo de amenizar essa problemática (CDURP, 2011).

De acordo com o projeto apresentado, a área do Porto Maravilha deverá beneficiar-se com a reurbanização de vias e calçadas; construção de túneis; reconstrução de redes de infraestrutura urbana de água, esgoto e drenagem; implantação de ciclovias; plantio de árvores; utilização de tecnologias de comunicação de última geração. Além disso, existem projetos especiais que incluem a recuperação do patrimônio e a construção das áreas culturais, como o Centro Cultural José Bonifácio; o Cais do Valongo/Imperatriz; os Galpões da Gamboa; o Museu do Amanhã; o Museu de Arte do Rio - MAR.

Eis os impactos no entorno previstos após a concretização das obras do Porto Maravilha:

- Aumento da população de 22 mil para cem mil habitantes em dez anos.

- Ampliação da área verde de 2,46\% para 10,96\% da área total.

- Aumento de 50\% na capacidade de fluxo de tráfego rodoviário na região.

- Redução da poluição do ar e da sonora, com a demolição do elevado da Perimetral e a diminui ção do transporte pesado na região.

- Aumento da permeabilidade do solo.

- Incremento e melhoria da qualidade da oferta de serviços públicos.

- Geração de empregos diretos e permanentes na região.

Já estão em andamento o restauro do Moinho Fluminense, Port Corporate, Port Brasilis, Porto Olímpico e a nova sede do Banco Central. Aguardando aprovação são aproximadamente $250 \mathrm{~m} 2$ em empreendimentos comerciais e residenciais. 


\section{Estudo FGV-ABREMAR: Cruzeiros marítimos no Brasil — Perfil da demanda}

Para conhecer o perfil do novo viajante, que se pode denominar de "marinheiros de primeira viagem", apresentam-se, de forma reduzida, os resultados da pesquisa encomendada pela Associação Brasileira de Cruzeiros Marítimos (ABREMAR) e pela Fundação Getulio Vargas (FGV) para a temporada 2010-2011.

Para tal, durante seis meses, aplicaram-se quatro mil questionários em cinco portos que receberam mais de $80 \%$ das escalas de navios na temporada brasileira 2010-2011. Identificou-se que, nesse período, houve uma movimentação de $R \$ 1,3$ bilhão para a economia do País. Desse total, $R \$ 791,6$ milhões foram gerados pelas armadoras e $\mathrm{R} \$ 522,5$ milhões pelos cruzeiros e tripulantes nos portos.

A pesquisa aponta também que as taxas e os impostos corresponderam a $\mathrm{R} \$ 215$ milhões de gastos totais das companhias marítimas, enquanto os combustíveis foram responsáveis por R\$290 milhões. As comissões, por sua vez, representaram R $\$ 122$ milhões do montante de gastos pelas armadoras, enquanto os cruzeiristas foram responsáveis pela movimentação de $R \$ 172,6$ miIhões no comércio varejista, seguidos pela área de bebidas e alimentação, com $R \$ 155,1$ milhões.

Beneficiadas, com os gastos dos cruzeiristas, foram, principalmente, as cidades portuárias, e, no topo da lista, destaca-se o Rio de Janeiro com $R \$ 102,9$ milhões e, em segundo lugar, a cidade de Santos, com $R \$ 86,6$ milhões.

Sobre o perfil dos turistas, a pesquisa identificou que:

- $58,8 \%$ são do sexo feminino,

- $54,4 \%$ são casados,

-58,1\% têm ensino superior,

• 33,7\% compõem a nova classe média.

Pode-se atribuir o aumento do fluxo de cruzeiristas às condições de financiamento e à forte presença publicitária. Outros dados são importantes destacar:

• 26,3\% dos hóspedes têm entre 25 e 34 anos,

• $33,7 \%$ têm renda entre $R \$ 2.500$ e $R \$ 5.000$,

-43,8\% viajaram acompanhados,

-62,7\% estavam pela primeira vez em um navio.

Outro dado, não menos importante, é que $88,9 \%$ dos hóspedes desceram dos navios em, 
pelo menos, um porto de escala durante a viagem. Questões geográficas também se revelaram, como o fato de o mercado de São Paulo ser o maior emissor de cruzeiristas, contabilizando 61,1\% dos passageiros da temporada 2010-2011 que embarcaram em Santos.

Esses dados, encontrados pela pesquisa FGV/ABREMAR, apontam a relevância de investir em mais pesquisas e estudos que sejam capazes de ampliar o espectro de conhecimentos sobre esse segmento do mercado turístico, a fim de municiar os agentes envolvidos com o máximo de informações. Avaliar o mercado e observar os resultados por ele trazidos pode ser entendido, portanto, como mecanismos-chave de desenvolvimento do setor de cruzeiros de cabotagem.

No estudo FGV-ABREMAR, identificou-se que foram considerados apenas os desafios provenientes da oferta de cruzeiros e não possíveis obstáculos impostos pela demanda. É esse o espaço que este artigo busca preencher: o de identificar os motivos que impedem as pessoas que nunca fizeram um cruzeiro de optar por esse tipo de viagem.

\section{Metodologia de pesquisa}

A metodologia de pesquisa é um dos alicerces que sustentam a validade científica das investigações, sejam teóricas ou empíricas. Assim, para atingir os resultados deste trabalho, foi enviado, por meio dos integrantes do grupo, com a utilização do canal eletrônico (mídias sociais - facebook e mailing/e-mails), um questionário com 25 perguntas fechadas e uma pergunta aberta com possibilidades de inserção de comentários. O questionário ficou disponível por um período de trinta dias, nos meses de dezembro e janeiro de 2012. A amostra de respondentes foi de residentes do estado do Rio de Janeiro que nunca viajaram em um cruzeiro, representando uma demanda potencial para o setor. Ao final, foram recebidos cem questionários válidos para estudo e elaboração das análises dos resultados, os quais serão abordados a seguir.

\section{Análise/resultados da pesquisa}

A fim de identificar os motivos pelos quais pessoas que nunca fizeram um cruzeiro não o consideraram como opção de viagem, os dados da pesquisa foram tabulados e os resultados serão apresentados a seguir. Para contextualizar as respostas obtidas, no entanto, faz-se necessário, primeiramente, apresentar o perfil da amostra da entrevista para, em seguida, relacionar com os apontamentos obtidos por meio da pesquisa. 


\subsection{Perfil dos entrevistados}

Após a tabulação dos questionários recebidos, observou-se que os respondentes tinham entre 25 e 34 anos e eram, na maioria, solteiros e com formação superior completa. Esse é um dado que coincide com a amostra da pesquisa da FGV quando analisou o perfil dos viajantes. Conforme é possível observar no Gráfico 1, a maioria dos entrevistados foi de mulheres, com $69 \%$ dos questionários preenchidos. Portanto, é importante observar que as respostas apresentadas ao longo do artigo deverão ser analisadas considerando fortemente a opinião do público feminino.

\section{Gráfico 1: Perfil dos entrevistados por sexo}

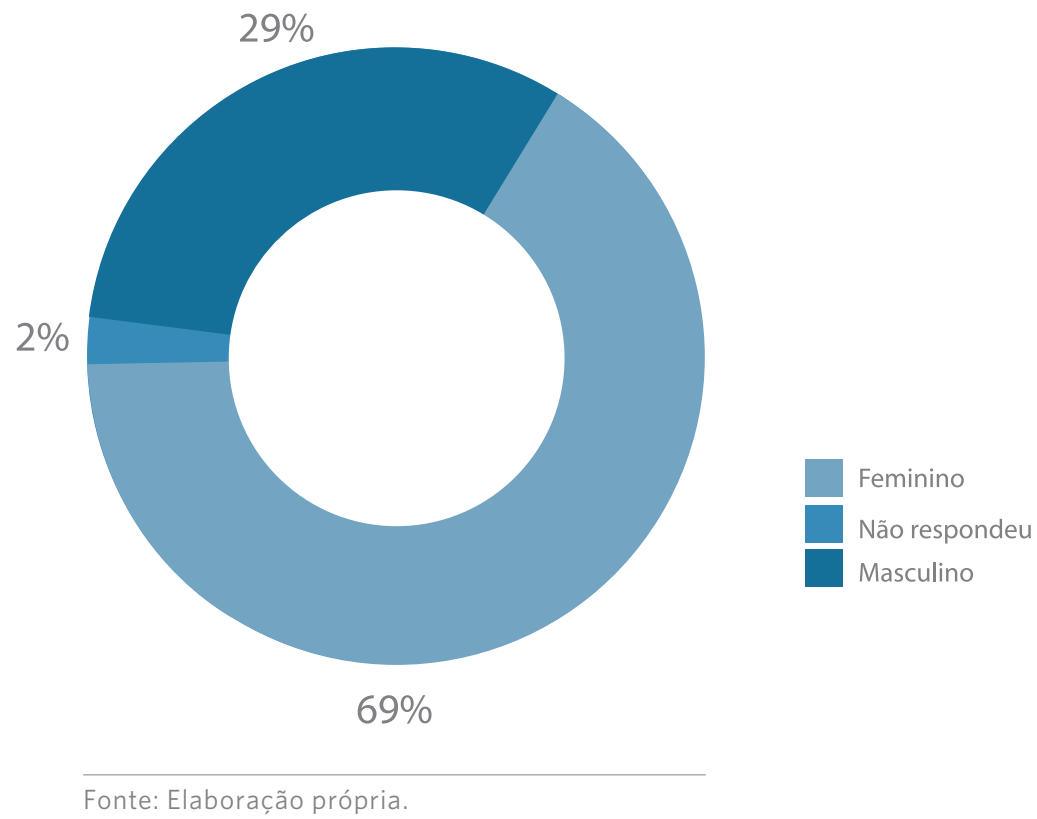

Esse índice é interessante ao cruzar-se com outras análises, tais como renda familiar e frequência de viagem, demonstrando que a idade do público, correspondente a pessoas no mercado de trabalho, é um potencial de atração para investimentos que gerem entretenimento/ lazer - por exemplo, os atuais navios temáticos, que têm atraído fortemente esse público.

Ainda complementando tais dados, 39\% dos entrevistados realizam regularmente uma viagem por ano, a maioria fazendo uso do transporte aéreo, o que demonstra que se trata de um público disposto a fazer viagens de longo curso, com dinheiro e tempo disponível. 


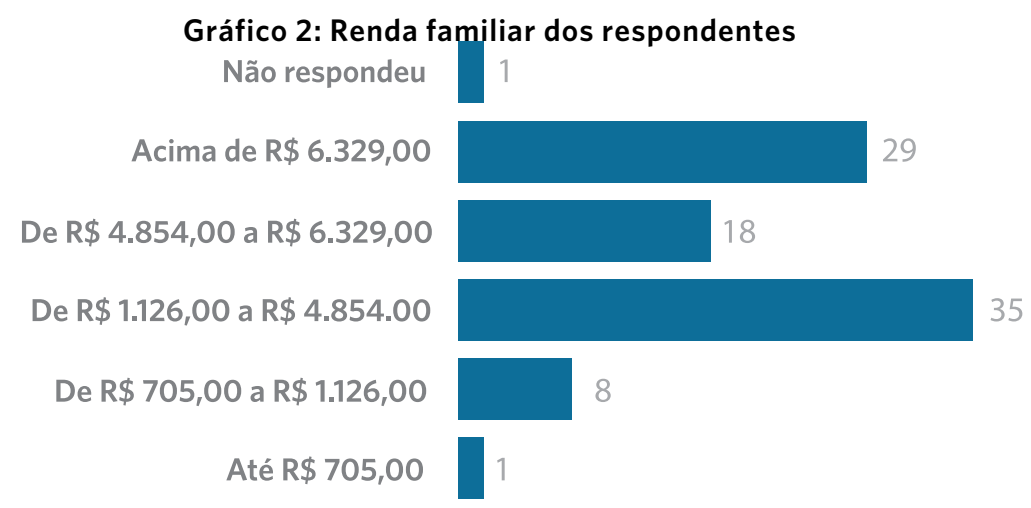

Fonte: Elaboração própria.

Considerando o que se abordou no texto sobre as classes B e C, que vêm demonstrando cada vez mais interesse em viagens, aqui os dados obtidos confirmam o interesse do novo segmento, ou seja, a renda de $35 \%$ dos entrevistados gira em torno de $R \$ 1.126,00$ reais a $R \$ 4.854,00$ reais. Ainda fazendo um paralelo com a pesquisa da FGV e ABREMAR, nota-se uma margem de ganhos bem parecida com a do público entrevistado.

\subsection{Resultados/APONTAMENTOS DA PESQUISA}

É interessante destacar, nesse momento, os principais apontamentos obtidos por meio da pesquisa. Os resultados demonstraram que $25 \%$ dos entrevistados apontaram o "custo alto da viagem", seguido de 19\% que mencionaram preferências por viagens aéreas e/ou terrestres (Gráfico 3). Esses dados sinalizam o quanto a atividade de cruzeiro, apesar de índices de crescimento, ainda sofre com a falta de informação. Possivelmente, para algumas pessoas, ainda impera a imagem predominante de preços altos e glamour, o que estigmatizava a viagem de cruzeiros como um produto quase inatingível. Assim, esse dado sugere que, para conquistar potenciais viajantes, as empresas marítimas devem usufruir de fortes ações de marketing no 


\section{Gráfico 3: Justificativas dos entrevistados para nunca terem feito um cruzeiro}

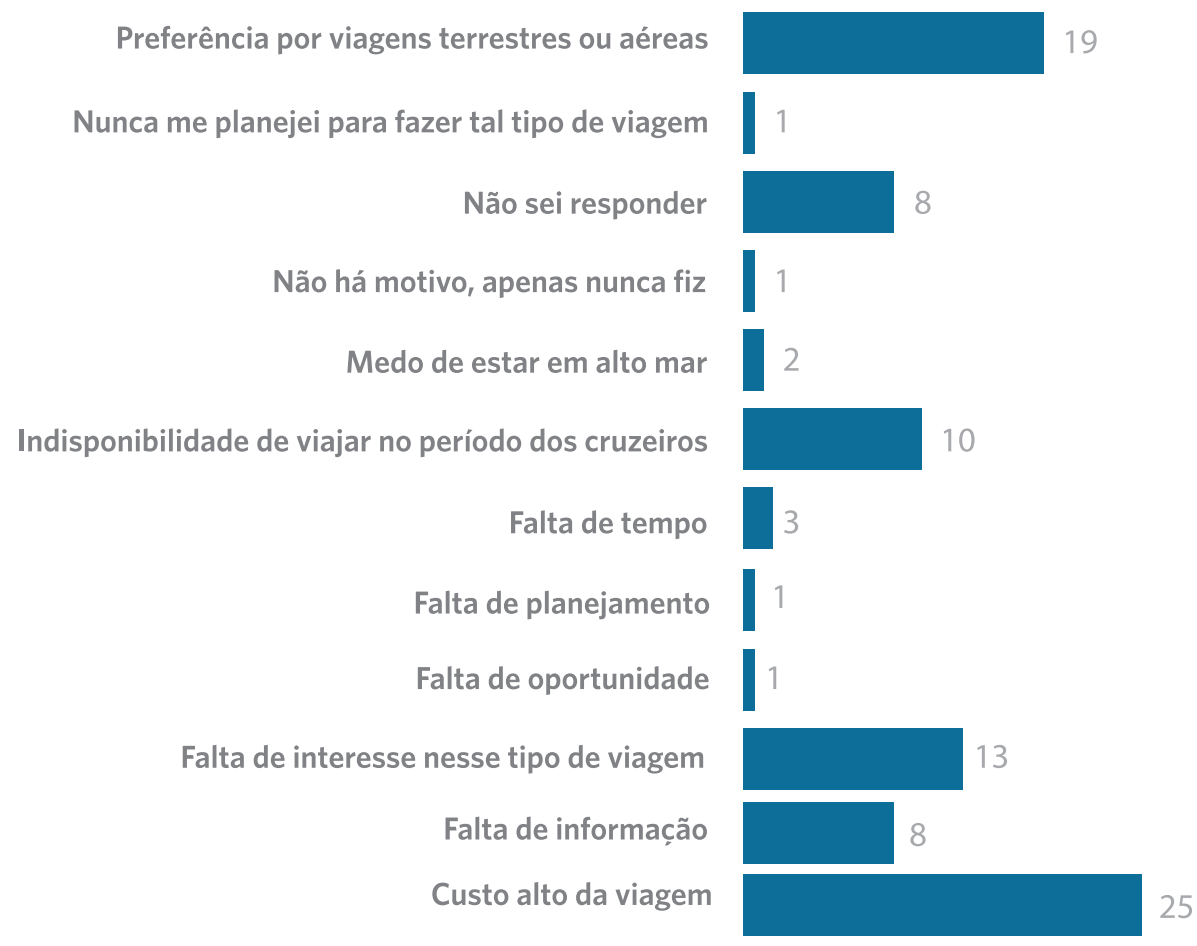

Fonte: Elaboração própria.

sentido de desconstruir a imagem distorcida e convencer a demanda potencial.

Quando indagados quanto aos fatores de motivação para realizar um cruzeiro, 41\% dos entrevistados alegaram a questão da oferta de preços mais baratos, enquanto $17 \%$ citaram a possibilidade de viagens mais curtas. Talvez esse público ainda não tenha percepção de que muitas empresas já oferecem pacotes com viagens de curta duração e com preços bastante atrativos, além de opções de financiamento. A questão do preço foi novamente citada aqui, reforçando a necessidade de desconstrução da imagem dos cruzeiros como produtos inacessíveis.

Para conquistar potenciais viajantes, as empresas marítimas devem usufruir de fortes ações de marketing, destacando principalmente as facilidades de prazo para pagamento, a programação anual de cruzeiros - o que ainda é bastante desconhecido por muitos - e até mesmo os lugares de compra. Vale ressaltar que as viagens aéreas, antes bastante restritas a algumas classes sociais, hoje são amplamente consumidas por grande parte da população, nas diversas classes sociais, em face de todas as facilidades já comentadas, o que vem atraindo cada vez mais pessoas que, antes, nunca tinham pensado em viajar. 
Gráfico 4: Fatores que poderiam motivar os entrevistados a realizarem um cruzeiro

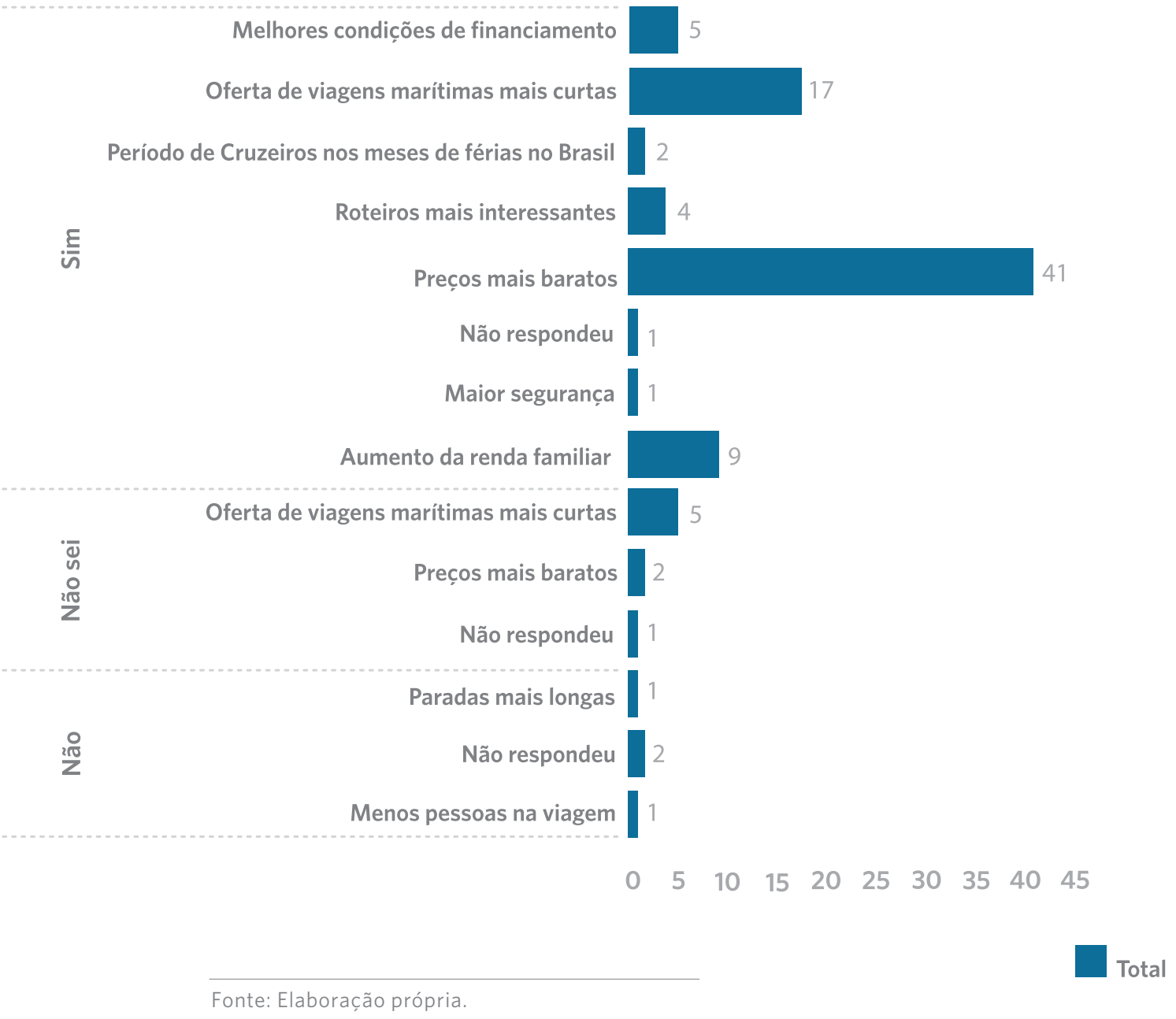

No Gráfico 5, demonstra-se que a maioria dos entrevistados manifestou o desejo de usufruir de todas as paradas do navio (63\%), com intenção de realizar a maior parte dos gastos em passeios turísticos para conhecer novos lugares (48\%), tendo como consequência direta a disposição para gastos com compras (14\%). Esses dados, se comparados à renda da maioria dos entrevistados, demonstra a possibilidade de movimentação da cadeia do turismo nas cidades de parada.

Essa constatação reforça os dados da pesquisa da FGV, na qual 88,9\% dos hóspedes desceram dos navios em, pelo menos, um porto de escala durante a viagem. Ambos os índices, ressaltam a importância do desenvolvimento da zona portuária, no caso o refletido no Projeto Porto Maravilha, 


\section{Gráfico 5: Interesse dos cruzeiristas nas paradas para entretenimento e lazer local}

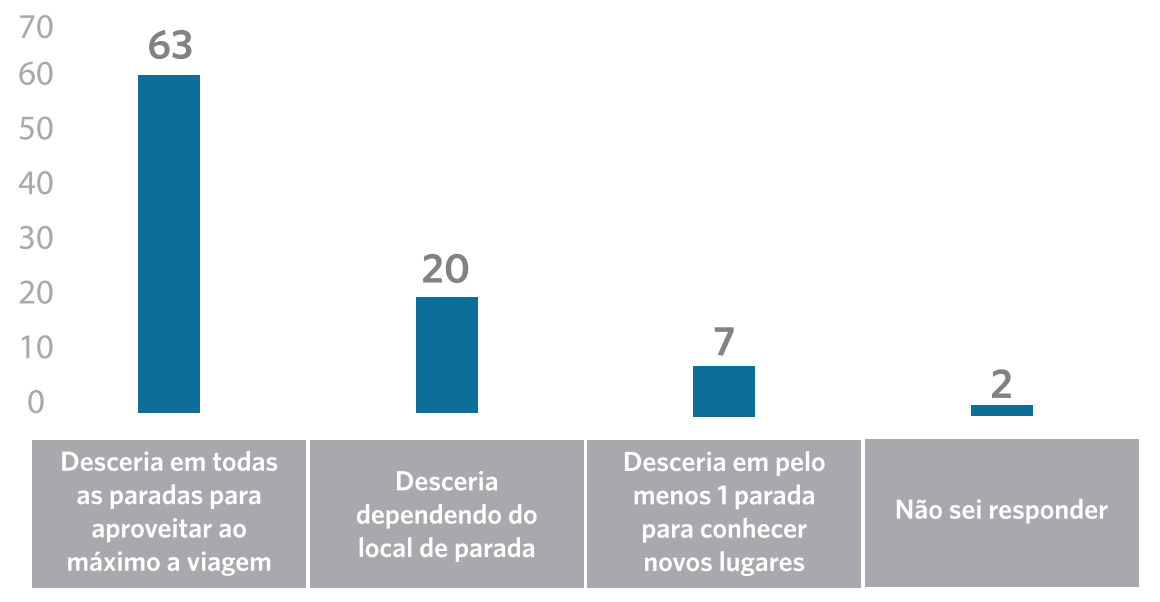

Fonte: Elaboração própria.

citado também neste trabalho, permitindo que viajantes de cruzeiros usufruam do mercado local.

No tocante à disposição para gastos fora do navio (Gráfico 6), o maior índice das respostas foi de $48 \%$, sinalizando que os futuros viajantes investiriam em passeios turísticos nas cidades visitadas. Esse dado é relevante e deve ser considerado em outras pesquisas, de forma mais detalhada, pois seria interessante ter um mapeamento geral dos gastos dos turistas hoje para que, em locais que atuam como portos de escala, se saiba planejar no sentido de promover melhores serviços, com intuito de maior arrecadação.

Ainda em relação a gastos externos, 10\% demonstraram propensão a realizar gastos com entretenimento. Já em relação aos gastos no navio, o maior índice $-6 \%$ - refere-se ao consumo de alimentos e bebidas.

\section{Gráfico 6: Disposição e preferência de gastos}

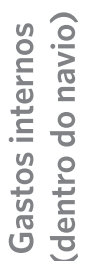

Passeios turísticos

Entretenimento

Compras

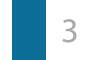

Alimentos e bebidas

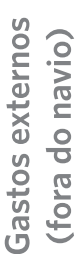

Passeios turísticos

Entretenimento



Compras

Alimentos e bebidas

Fonte: Elaboração própria. 
Por mais que a demanda pela atividade de cruzeiro esteja crescendo, conforme citado no início do trabalho, ainda aparece na pesquisa um dado para reflexão, visto que $19 \%$ dos entrevistados mencionaram a intenção de, em um ano, realizar uma viagem em cruzeiro, seguidos de $33 \%$ que tencionam fazê-lo nos próximos dois anos. Esses dados revelam o quanto a atividade ainda requer uma maior divulgação, por causas ainda não conhecidas, pois fica claro a não prioridade desse tipo de viagem. Vale destacar que, na pesquisa da FGV, apontou-se que $62,7 \%$ dos entrevistados estavam pela primeira vez em um navio. Ou seja, sinaliza que esse tipo de viagem ainda não é tão comum.

\section{Gráfico 7: Intenção futura de viajar em cruzeiro}



Fonte: Elaboração própria.

Essa afirmação pode ser reforçada pelo Gráfico 8, que complementa o anterior, em que se demonstra que, em relação ao grau de desejo de viajar em um cruzeiro, 30\% dos entrevistados mencionaram ter "muita vontade", enquanto 25\% demonstraram "muitíssima vontade", seguidos de $21 \%$ com "vontade mediana". Ao considerarem-se os dados anteriores, existe uma conformidade, já que a maioria pretende viajar apenas nos próximos dois anos.

Como forma de ampliar o desejo e acelerar a previsão de viagem nesse público em potencial, faz-se necessário que as empresas de cruzeiros invistam em pesquisas, a fim de elaborar planos de marketing que visem a reforçar essas ações. Vale ressaltar que, de acordo com noticiários, em 2012, os aeroportos bateram recordes de viagens. Esse público poderia ser dividido com os cruzeiros. 


\section{Gráfico 8: Grau de vontade de viajar num cruzeiro}

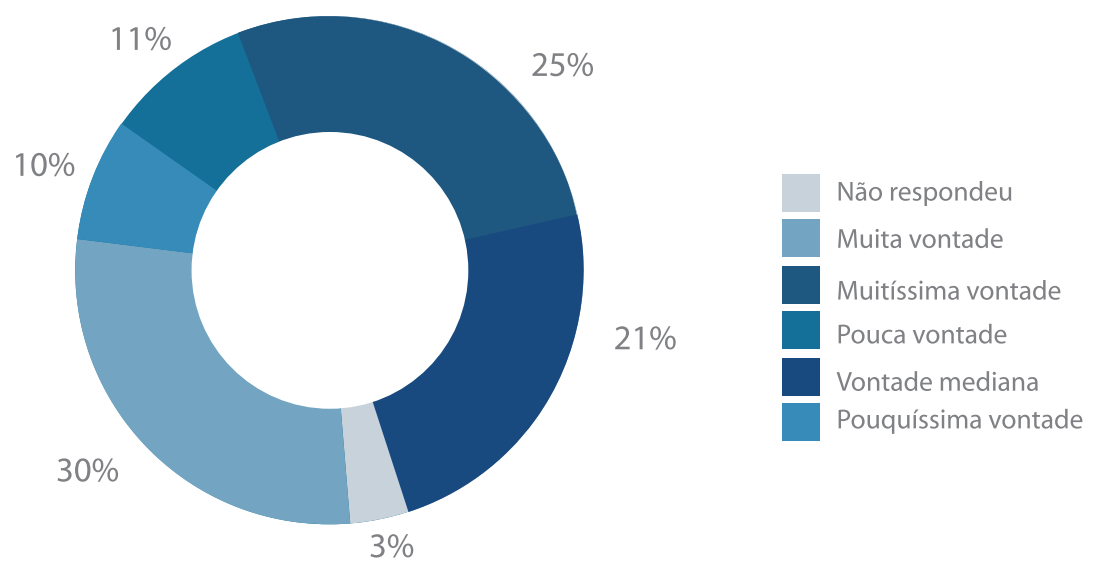

Fonte: Elaboração própria

Um aspecto interessante detectado na amostra da pesquisa confirma o que já sabemos, ou seja, os grandes concorrentes das viagens marítimas continuam sendo os atuais resorts: $59 \%$ do público revelam ainda preferir esse produto em detrimento dos cruzeiros, possivelmente motivados pelas fortes investimentos em propaganda nas principais revistas e jornais.

Esses dados confirmam a necessidade de uma ação empreendedora para lançar uma ação estratégica em uma demanda antes reprimida, mas que tem potencial consumidor. Reiterando essa concepção, apresenta-se a definição do economista moderno , Joseph Schumpeter:

[...] o empreendedor é aquele que destrói a ordem econômica existente pela introdução de novos produtos e serviços, pela criação de novas formas de organização ou pela exploração de novos recursos e materiais (SCHUMPETER, 1949 apud DORNELAS, 2001, p. 37).

\section{Gráfico 9: Preferência entre viagem de cruzeiro e resort}

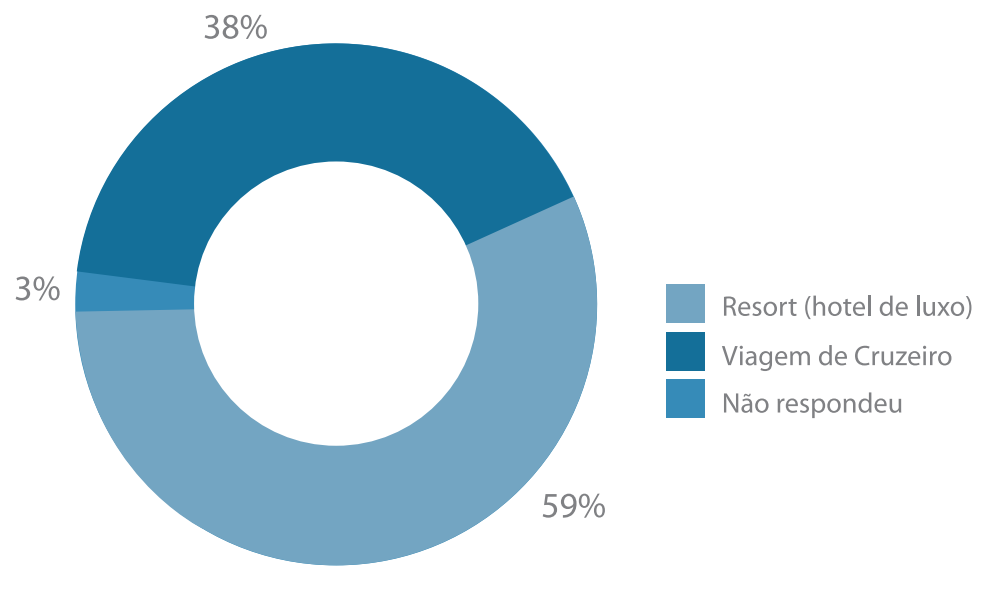

Fonte: Elaboração própria. 
Na perspectiva de realizar um cruzeiro marítimo, um dos itens interessantes que desperta esse desejo está ligado, principalmente, à questão de segurança, pois 30\% dos entrevistados pontuaram a viagem marítima como "muito segura" e 30\%, como "segura". Ressalte-se também que $48 \%$ dos entrevistados não têm preferência por determinada companhia de turismo. É importante mencionar que, embora uma viagem de navio seja algo bastante atraente no imaginário das pessoas, a maioria dos interessados ainda não conhece as companhias marítimas atuantes no Brasil, bem como os serviços oferecidos nos cruzeiros. Comparando-se, mais uma vez, com o setor aéreo, em que as empresas são conhecidas pelo público, justifica-se a necessidade de reforçar e/ou criar a identidade dos armadores.

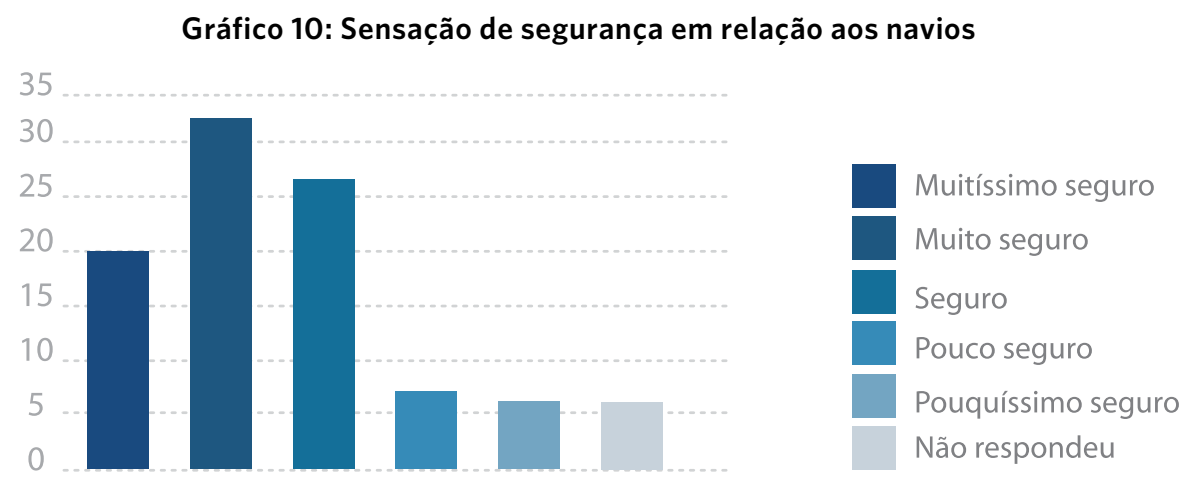

Fonte: Elaboração própria

Os dados até aqui apresentados serviram para demonstrar que os motivos pelos quais a potencial demanda do estado do Rio de Janeiro ainda não motivou uma viagem de cruzeiro estão ligados à falta de informação em relação aos custos, às vantagens e às condições de pagamento reais desse tipo de viagem. Reforça-se, pois, a necessidade de desconstrução da imagem do cruzeiro, tanto em relação ao fato de ser considerado um produto voltado para classe $A$, quanto em relação às características da viagem - que fazem com que algumas pessoas julguem não se adequar ao modelo de lazer dos cruzeiros. Investir em ações de marketing para antecipar a decisão do consumidor em potencial e vencer a concorrência em relação aos resorts mostra-se um desafio para ampliar o crescimento do setor.

\section{Considerações finais}

Os cruzeiros marítimos são um importante segmento para o crescimento do turismo no Brasil, e o estudo desse setor é fundamental para a compreensão da complexidade do tema, a fim de identificar os posicionamentos favoráveis e contrários a seu desenvolvimento, tema de constantes discussões no trade. Ressalte-se, portanto, a necessidade de investimentos em 
pesquisas que sejam capazes de prover a todos os agentes envolvidos com grande número de informações para obterem-se melhores resultados e rentabilidade.

Neste trabalho, buscou-se verificar os entraves ao desenvolvimento do mercado de cruzeiros no Brasil relacionados com a demanda, identificando os principais fatores que impedem ou adiam a decisão por realizar a viagem por parte das pessoas que ainda não o fizeram.

Durante a pesquisa, verificou-se que houve elevação na demanda e crescimento do setor de cruzeiros no País, ocasionados em grande parte pelo aumento do poder aquisitivo de uma parcela da população e pelas facilidades de financiamento das viagens. Apesar disso, ainda existem alguns problemas que inibem o crescimento, entre os quais se destacam os de infraestrutura e custos operacionais.

Por meio dos resultados obtidos na pesquisa, pode-se observar que, na amostra pesquisada, as pessoas se mostram propensas a realizar um cruzeiro. No entanto esse tipo de viagem ainda não parece ser prioridade para a maioria dos entrevistados. Além disso, é necessário observar os fatores apontados como decisivos para que a potencial demanda de fazer essa viagem, como diminuição de preço, oferta de cruzeiros na baixa temporada, falta de interesse e informação, a fim de que os armadores voltem seus esforços de marketing e promoção, podendo dessa forma ampliar ainda mais a demanda, bem como vencer a concorrência em relação aos resorts.

Se compararmos os principais resultados da pesquisa com o perfil da demanda real apresentado no estudo da FGV e ABREMAR, é possível constatar que as expectativas mencionadas pelas pessoas que nunca fizeram um cruzeiro se confirmam, como o fato de a maioria descer nas cidades dos roteiros. Na pesquisa da FGV, também ficou demonstrado que a maioria dos passageiros tem intenção de realizar outra viagem de cruzeiro. Tal fator reforça a necessidade de mais informação para que os futuros viajantes conheçam os pontos positivos desse tipo de viagem e tomem a decisão de viajar, já que, na pesquisa, as pessoas demonstraram não ter informação ou noção real dos benefícios, e, inclusive, revelaram certos preconceitos em relação à viagem, pensando que não é tão divertida, ou que não há tanta liberdade quanto em terra.

Cabe destacar que, com base no conjunto de dados obtidos e nas análises estatísticas efetuadas, o quantitativo de questionários respondidos e a investigação limitada apenas ao estado do Rio de Janeiro restringiram a abrangência do estudo. Apesar disso, espera-se, com este trabalho, iniciar e incentivar a discussão sobre os limites de expansão do segmento de cruzeiros no País. Aqui se focou em anseios e necessidades do turista em potencial. Para obterem-se respostas mais consistentes, sugere-se desenvolver pesquisas em um número maior de estados brasileiros, porque possibilitará identificar razões distintas pelas quais as pessoas não optam por realizar um cruzeiro.

Uma hipótese que pode ser investigada em pesquisas futuras é em relação à distância de determinadas cidades em relação a portos de embarque. Por meio de pesquisas, os armadores poderão identificar novos mercados ou a necessidade de formatação de novos produtos, de acordo com as respostas do público-alvo. 


\section{Referências}

ABREMAR. Infraestrutura portuária no Brasil. 1. e versão, p. 1-105, nov. 2010.

Relatório cruzeiros marítimos: estudo de perfil e impactos econômicos no

Brasil. FGV/Projetos - Fundação Getulio Vargas, 2011.

AMARAL, R. Cruzeiros marítimos. Barueri: Manole, 2002.

BOITEUX, B. (2010). O Brasil, os cruzeiros e o turismo. BRASILTURIS JORNAL. Disponível em: http://www.brasilturis.com.br/edicaomateria_materia.neo?Materia=190. Acesso em: 14 fev. 2012.

BRIDA, J. et al.(2010). Impactos económicos del turismo de cruceros. Estudios y Perspectivas en Turismo, vol. 19, p. 607-634, 2010.

CDURP Porto Maravilha. 2011. Disponível em: http://www.portomaravilha.com.br/ web/sup/OperUrbanaApresent.aspx. Acesso em: 18 fev. 2012.

CPRJ. Disponível em: https://www.cprj.mar.mil.br/arquiv/npcp/cap4.pdf. Acesso em: 18 fev. 2012.

KESTER, J. Cruise tourism. Tourism Economics, vol. 9, n.o 3, p. 337-350, 2002.

MATTOS, F. (2009). A invasão dos cruzeiros de cabotagem e o efeito devastador do câmbio

no turismo brasileiro. Disponível em: http://floripamanha.org/2009/10/a-invasao-dos-cruzeiros-de-cabotagem-e-o-efeito-devastador-do-cambio-no-turismo-brasileiro/. Acesso em: 14 fev. 2012.

MTUR. Turismo náutico. Disponível em: http://www.turismo.gov.br/turismo/programas_acoes/regionalizacao_turismo/estruturacao_segmentos/nautico. Acesso em: 14 fev. 2012.

\footnotetext{
Fabiana Braga Leal

Pós-graduanda em Turismo, Hotelaria e Entretenimento pelo Observatório de Inovação e Turismo - OIT/ EBAPE/FGV: graduada em Hotelaria pela UNESA com chancelaria pela Ecole Hôtelière de Lausanne; assistente editorial da Revista de Administração Pública - RAP - e Cadernos EBAPE.BR e pesquisadora do Grupo de Estudos Internacionais - GEI. Endereço: Praia de Botafogo, 190/sala 538, Rio de Janeiro-RJ/Brasil. CEP: 22250-900.E-mail: fabi.leal@hotmail.com.
}

\section{Maria de Fatima Soares}

Pós-graduanda pelo Observatório de Inovacão do Turismo - OIT/EBAPE/FGV; MBA executivo com ênfase em Marketing de Serviços pela Escola Superior de Propaganda e Marketing (ESPM); Pós-graduada em Administração Empresarial pela Universidade Federal Fluminense (UFF) e em Ensino a Distância pelo SENAC; graduada em Português e Literatura pela Universidade Estadual do Rio de Janeiro (UERJ). Atualmente trabalha na empresa Amadeus Brasil, atuando como responsável pela capacitação das agências de viagens no Sistema de Reservas Amadeus (GDS).E-mail: soaressalgado@bol.com.br.

\section{Natalia Pacheco}

Cientista social, graduada pela UERJ; turismóloga, formada pela UFF; mestre em Ciências Jurídicas e Sociais pelo Programa de Pós-Graduação em Sociologia e Direito (PPGSD/UFF); doutoranda em Ciência Política pelo Instituto de Estudos Sociais e Políticos (IESP/EURJ) e pós-graduanda do Observatório de Inovação do Turismo - OIT/EBAPE/FGV); coordenadora e docente do Curso Superior de Tecnologia em Gestão de Turismo da Anhanguera Educacional (Unidade Niterói/UNIPLI), com dedicação concomitante à Educação a Distância (EAD) como docente on-line do IBMEC-RJ. E-mail: profnataliapacheco@gmail.com.

\section{Teresa Catramby}

Doutora em Engenharia de Produção pela COPPE/UFRRJ; pesquisadora do NEPET/IM/UFRRJ e do LTDS/COPPE/UFRJ; professora do curso de Turismo da UFRRJ.E-mail: teresacatramby@gmail.com.

\section{Thays Venturim Guimarães}

Mestranda em Administração pela EBAPE/FGV; pós-graduanda pelo Observatório de Inovação do Turismo - OIT/EBAPE/ FGV; bacharel em Turismo pela Universidade Federal Fluminense - UFF; consultora e pesquisadora do Núcleo de Turismo da FGV Projetos. E-mail: <thays_venturim@yahoo.com.br>. 


\section{Apêndice I - Tabela 2: Descrição do porto e terminais turísticos}

\begin{tabular}{|c|c|c|c|c|c|}
\hline $\begin{array}{l}\text { PORTO/TERMINAL } \\
\text { TURÍSTICO }\end{array}$ & INFRAESTRUTURA & PÍER & $\begin{array}{l}\text { CANAL DE } \\
\text { ACESSO AO } \\
\text { PÍER }\end{array}$ & $\begin{array}{l}\text { BACIA DE } \\
\text { EVOLUC̣ÃO }\end{array}$ & $\begin{array}{l}\text { AMPLI- } \\
\text { TUDE DE } \\
\text { MARÉ }\end{array}$ \\
\hline Rio de Janeiro & $\begin{array}{l}\text { Píer Mauá: ônibus para trans- } \\
\text { porte dos passageiros (terminal } \\
\text { x navio); ambulatório e serviço } \\
\text { de UTI 24h por dia; balcões para } \\
\text { check-in e informações turísticas; } \\
\text { lanchonetes e lojas de souvenir, } \\
\text { cabines para ligações nacionais, } \\
\text { internacionais e Internet; serviço } \\
\text { de imigração, Alfândega e Polícia } \\
\text { Federal; vigilância sanitária; } \\
\text { heliporto; aparelhos de raios X } \\
\text { para checagem das bagagens; } \\
\text { defensas fixas e móveis para } \\
\text { aluguel. }\end{array}$ & $\begin{array}{l}\text { Píer Mauá: } 550 \text { m de } \\
\text { extensão (cabeços } 36 \\
\text { a } 58 \text { do cais comer- } \\
\text { cial) e berço para até } \\
\text { cinco navios (exceção } \\
\text { do primeiro sábado } \\
\text { de fevereiro de 2012) } \\
\text { comportando seis } \\
\text { navios de cruzeiro } \\
\text { (relato dos autores). } \\
\text { A distância do píer até } \\
\text { o desembarque é de } \\
\text { cinquenta a duzentos } \\
\text { metros. }\end{array}$ & $\begin{array}{l}\text { Canal com vinte } \\
\text { a } 37 \text { metros de } \\
\text { profundidade. }\end{array}$ & $\begin{array}{l}\text { Com dez a } 37 m \\
\text { de profundidade e } \\
1.150 \text { m de largura. }\end{array}$ & Até $1,3 \mathrm{~m}$. \\
\hline Búzios & $\begin{array}{l}\text { Defensas móveis de pneu e há } \\
\text { toldos como cobertura. }\end{array}$ & $\begin{array}{l}\text { Píer Porto Veleiro } \\
\text { (privativo): de madeira } \\
\text { e com três posições } \\
\text { para tênderes. } \\
\text { Píer Municipal: de } \\
\text { concreto e com } \\
\text { duas posições para } \\
\text { tênderes. }\end{array}$ & $\begin{array}{l}\text { Canal com nove } \\
\text { metros de pro- } \\
\text { fundidade. }\end{array}$ & Sem descrição. & $\begin{array}{l}\text { Média um } \\
\text { metro. }\end{array}$ \\
\hline Ilha Grande & & $\begin{array}{l}\text { Pier do Abraão: de } \\
\text { madeira com duas } \\
\text { posições para tên- } \\
\text { deres. }\end{array}$ & Sem descrição. & $\begin{array}{l}\text { Com } 10,5 \mathrm{~m} \text { de pro- } \\
\text { fundidade e } 315 \mathrm{~m} \\
\text { de largura. }\end{array}$ & Até $1,1 \mathrm{~m}$. \\
\hline Angra dos Reis & $\begin{array}{l}\text { Píer Santa Luzia: informações } \\
\text { turísticas e banheiros; } \\
\text { Píer Pirata's Mall (privativo): sem } \\
\text { terminal de passageiros. }\end{array}$ & $\begin{array}{l}\text { Porto de Angra dos } \\
\text { Reis: com dois berços } \\
\text { de atracação. }\end{array}$ & $\begin{array}{l}\text { Porto Angra } \\
\text { dos Reis: com } \\
\text { duas barras de } \\
\text { entrada (uma } \\
\text { a leste e outra } \\
\text { a oeste da llha } \\
\text { Grande). }\end{array}$ & $\begin{array}{l}\text { Porto Angra dos } \\
\text { Reis: com dez } \\
\text { metros de profun- } \\
\text { didade e } 320 \mathrm{~m} \text { de } \\
\text { largura. }\end{array}$ & Até 1,1m. \\
\hline Cabo Frio & $\begin{array}{l}\text { Terminal Cabo Frio: banheiros } \\
\text { com acessibilidade; restau- } \\
\text { rantes e lanchonetes; Polícia e } \\
\text { Receita Federal, ANVISA, agente } \\
\text { marítimo, serviços de primeiros } \\
\text { socorros; segurança privada; } \\
\text { estrutura para transportes e } \\
\text { estacionamento (ônibus, carros } \\
\text { e vans); defensas móveis de pneu. }\end{array}$ & $\begin{array}{l}\text { O píer é de concreto e } \\
\text { a passarela de madei- } \\
\text { ra com três posições } \\
\text { para tênderes. }\end{array}$ & $\begin{array}{l}\text { Canal com } \\
\text { quatro metros de } \\
\text { profundidade e } \\
25 \text { m de largura. }\end{array}$ & Sem descrição. & $\begin{array}{l}\text { Média um } \\
\text { metro. }\end{array}$ \\
\hline Paraty & $\begin{array}{l}\text { O canal é crítico por causa da } \\
\text { presença de lajes, ilhas e pontas } \\
\text { da costa que estreitam o mesmo } \\
\text { para cem metros de largura em } \\
\text { determinadas posições. O calado } \\
\text { máximo na cabeceira da ponte é } \\
\text { de cerca de dois metros. }\end{array}$ & $\begin{array}{l}\text { De madeira com } \\
\text { posições para quatro } \\
\text { embarcações. }\end{array}$ & $\begin{array}{l}\text { Demarcado na } \\
\text { carta náu- } \\
\text { tica DHN } 1.633 \\
\text { com aproxi- } \\
\text { madamente } \\
\text { cinco metros de } \\
\text { profundidade e } \\
\text { diminuindo para } \\
\text { dois metros, } \\
\text { próximo à ponte. }\end{array}$ & Sem descrição. & $\begin{array}{l}\text { Média um } \\
\text { metro. }\end{array}$ \\
\hline
\end{tabular}

